\title{
Неархейские конгломерато-брекчии Чунозерской зоны (Кольский регион северо-восточной части Фенноскандинавского щита)
}

\section{Пожиленко В.И.}

Геологический институт КНЦ РАН, Anamumbl, pozhil@geoksc.apatity.ru

Аннотация. Чунозёрская зона расположена в центральной части Кольского региона. В ней выявлены и описаны два участка с конгломератобрекчиями:1 - на г. Руапнюн (32॰15'20" E longitude, 6743’35'” N latitude); 2 - на г. Ельявруайвенч (3240’50’’ E longitude, 67³9’20’’ N latitude). Они аналогичны конгломератобрекчиям 2-ой толщи Вочеламбинского зеленокаменного пояса..

Ключевые слова: Фенноскандинавский щит, Кольский регион, неоархей, конгломерато-брекчия, эруптивная брекчия.

\section{Neoarchean conglomerate breccias of the Chunozero zone (Kola region of the North-Eastern part of the Fennoscandian Shield)}

\author{
Pozhilenko V.I. \\ Geological Institute of the Kola scientific centre, RAS, Apatity,pozhil@geoksc.apatity.ru
}

Abstract. The Chunozero zone is located in the central Kola Peninsula. Conglomerate-breccias have been discovered and studied in two areas within this zone (the first is situated on the Ruapnyun mountain, 32 $15^{\circ} 20^{\prime \prime}$ E,

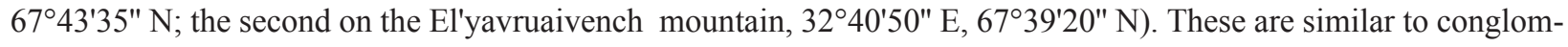
erate-breccias in the second unit of the Voche-Lambina greenstone belt.

Key words: Fennoscandian Shield, Kola region, neoarchaean, conglomerate-breccia, eruptive breccia.

\section{Введение}

В процессе тематических исследований в Чунозёрской зоне центральной части Кольского региона были закартированы обнажения конгломерато-брекчий. По петрографическому составу преобладают конгломерато-брекчии типа туфоконгломератов (рис. 1) с наличием участков похожих на брекчии со слабо окатанными обломками (рис. 2).

Наиболее достоверными и интересными являются два участка конгломерато-брекчий: 1) ксенолит ( 3 м ×10 м) конгломерато-брекчий в метаморфизованных габброидах в 950 м к востоку от южного окончания оз. Ельявр на г. Ельявруайвенч (3240'50" восточной долготы, 67³9'20" северной широты) (рис. 3); 2) останец $(\sim 150 \times 15-40$ м), а в 70 м к северо-востоку от него на западном склоне г. Руапнюн - линза ( 20×100м) (32¹5'20" восточной долготы, 6743'35" северной широты)

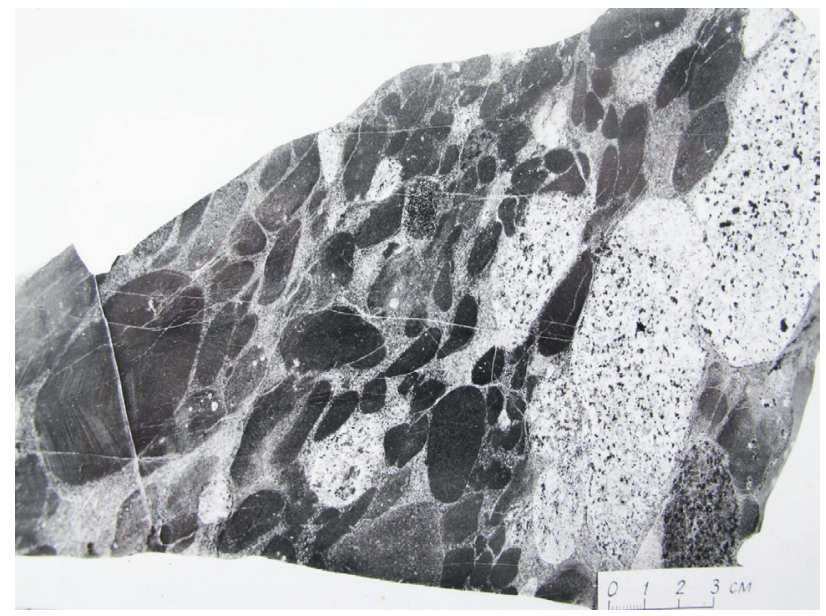

Рис. 1. Фотография крнгломерато-брекчий.

Fig. 1. Image of conglomerate-breccias.

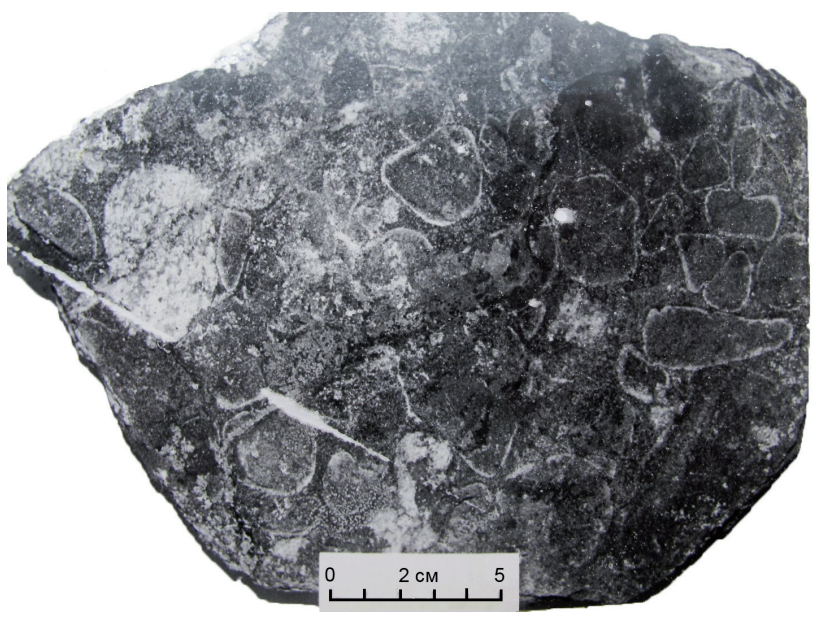

Рис. 2. Фотография крнгломерато-брекчий.

Fig. 2. Image of conglomerate-breccias. 
конгломерато-брекчий в окружении габброидов (рис. 4). Положение этих обнажений показано на геологической карте (Пожиленко и др., 2002, рис. 3). Краткая геологическая и петрографическая характеристика этих обнажений приведена в работах (Пожиленко, 2007 a, 2007 б).

\section{Возраст конгломерато-брекчий}

Конгломерато-брекчии г. Руапнюн прорваны габброноритами (позднее амфиболизированными), друзитовыми метагаббро, габбро-диабазами (долеритами) и плагиомикроклиновыми гранитами. Габбронориты по петрохимическим признакам аналогичны габброноритам Вочеламбинского зеленокаменного пояса (ВЗП), возраст которых $2491 \pm 13$ млн. лет (Кислицын и др., 2000). Это может свидетельствовать о более раннем образовании конгломерато-брекчий.

Морфотипы цирконов из одного валуна имеют возраста $2515 \pm 55,2500 \pm 100,2520 \pm 40$ млн. лет, из галек - 2.4-2.5 млрд. лет, а из самого крупного валуна второй морфотип циркона имеет возраст $2750 \pm 50$ млн. лет. Если предполагать, что образование цирконов с возрастом около 2.4-2.5 млрд. лет произошло в результате прогрева в процессе термального метаморфизма, а воз-

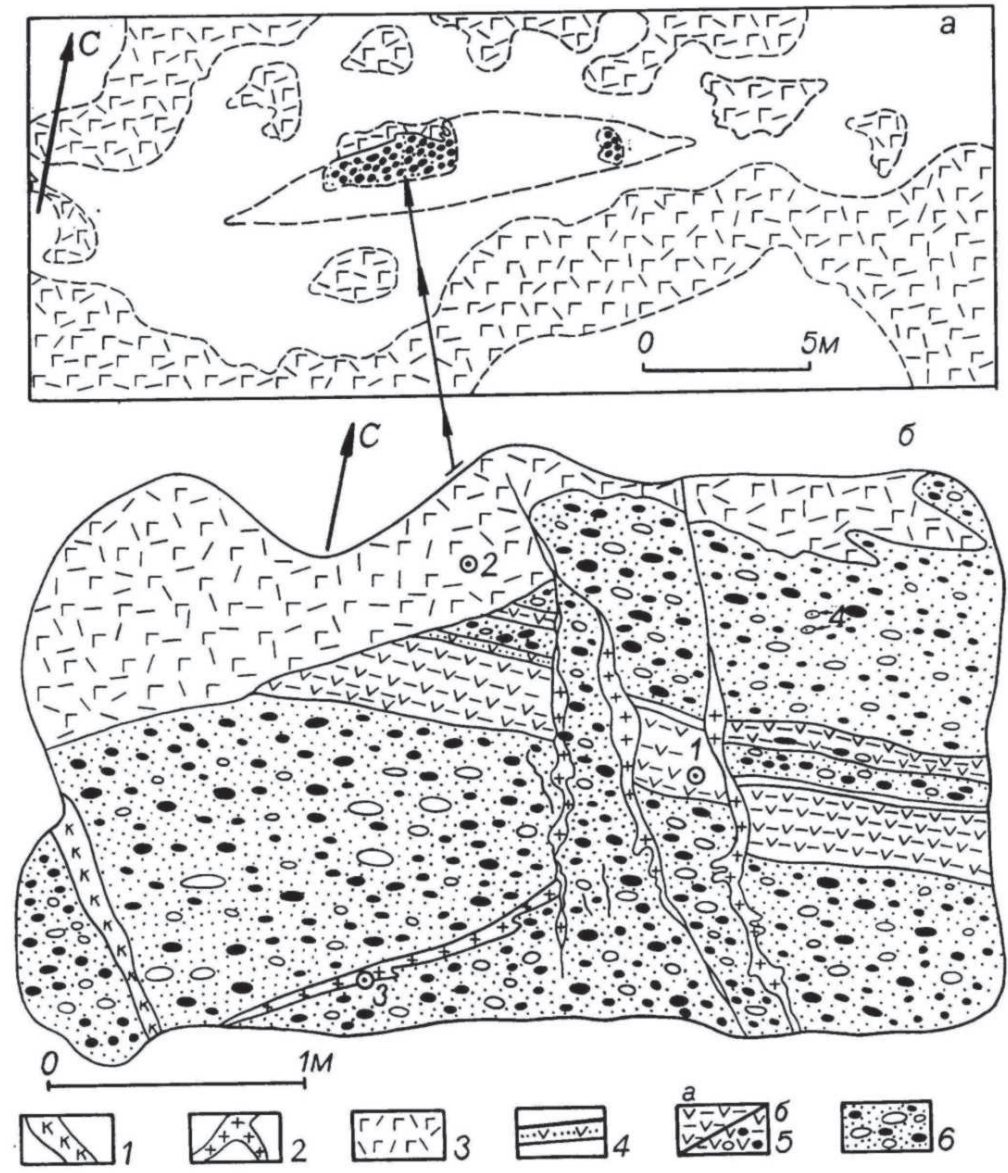

Рис. 3. Геологическая схема участка (а) и зарисовка обнажения (б) конгломерато-брекчий г. Ельявруайвенч Чунозёрской зоны.

1 - кварцевая жила; 2 -жилки плагиогранитоидов; 3 - тёмно-серый амфиболит по габбро-диабазу; 4 - мелкозернистые амфиболиты по прослою туффитов; 5 - тёмно-серый мелкозернистый амфиболит по мелкозернистому туфу (а), с редкими гальками гранитоидов и обломками туфов (б); 6 - полимиктовые, несортированные конгломерато-брекчии с пирокластикой (туфоконгломераты).

Fig. 3. Geological map of the site (a) and drawing of the outcrop (b) conglomerate-breccias of the town of Elyavruaivench of the Chunozero zone.

1 - quartz vein; 2 - plagiogranitoid veins; 3 - dark gray amphibolite by gabbro-diabase; 4 - fine-grained amphibolites by the uffite interlayer; 5 - dark gray fine-grained amphibolite by the fine-grained tuff (a), with rare granitoid pebbles and tuff fragments (b); 6 - polymictic, unsorted conglomerate-breccias with pyroclastics (tuff conglomerates). 

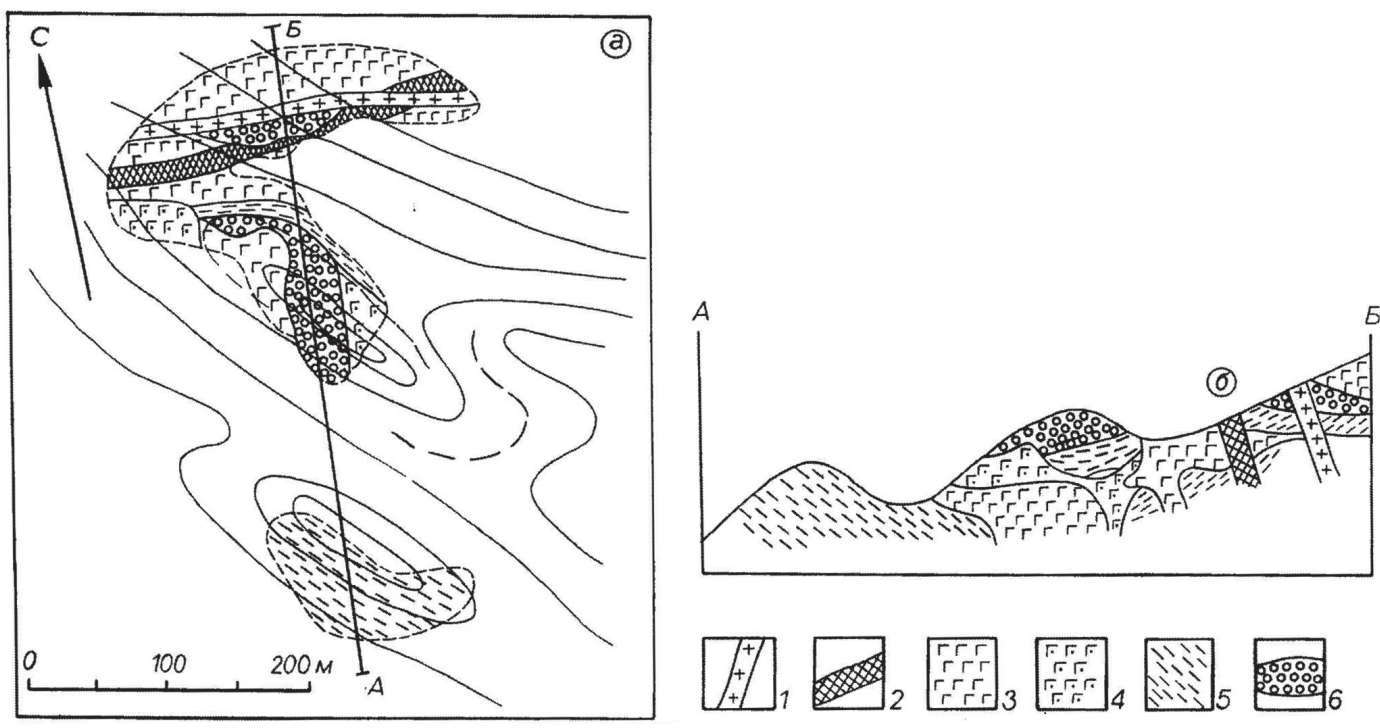

Рис. 4. Геологическая схема участка (а) и разрез (б) конгломерато-брекчий горы Руапнюн Чунозёрской зоны. 1 - плагио-микроклиновые гранитоиды; 2 - габбро-диабазы; 3 - габбро амфиболизированное; 4 - метагаббро; 5 - полевошпатовые полосчатые амфиболиты и мезократовые амфиболовые сланцы (по базальтоидам, туфам, габброидам); 6 - конгломерато-брекчии.

Fig. 4. Geological scheme of the plot (a) and section (b) conglomerate-breccias of the Ruapnyun Mountain, Chunozero zone. 1 - plagiomicrocline granites; 2 - gabbro-diabases; 3 - amphibolized gabbro; 4 - metagabbro; 5 - feldsparbanded amphibolites and mesocratic amphibolite shales (by basaltoids, tuffs, gabbroids); 6 - conglomerate breccias.

раст циркона $2750 \pm 50$ млн. лет фиксирует время кристаллизации гранитов, то образование конгломерато-брекчий произошло в интервале 2.75-2.5. млрд. лет, т.е. в позднеархейское (позднелопийское) время.

\section{Природа конгломерато-брекчий}

Для определения состава пород областей сноса (источников метаконгломерато-брекчий) и сопоставления состава обломочного материала метаконгломерато-брекчий с архейскими метаконгломератами Кольского региона и древнейшими гранитоидами были проанализированы гальки и обломки, преобладающие в составе метаконгломерато-брекчий (табл. 1).

По щелочному модулю и содержанию кремнекислоты обломки плагиогранитоидов соответствуют тоналитам и плагиогранитам инфракомплекса и обломкам аналогичных пород из конгломерато-брекчий Вочеламбинского зеленокаменного пояса (рис. 5). Но по содержанию Rb и $\mathrm{Sr}$ они подобны тоналитовым плутонам провинции Барбертон и в меньшей степени древнейшим гранитам и тоналитам Карелии и Кольского полуострова (рис. 6). Угловатые обломки метабазитов по соотношению щелочей и кремнезёма, а также по некоторым другим петрогенным элементам, аналогичны обломкам амфиболитов из конгломерато-брекчий и амфиболитам второй толщи Вочеламбинского зеленокаменного пояса.

\section{Выводы}

Находки в районе г. Руапнюн (в прикровлевой части интрузии), а также в районе г. Ельявруайвенч и отрога Ельнюн-ІІ (в прикровлевой части габбрового массива Ельнюн) крупных ксенолитов конгломерато-брекчий и реликтов полосчатых амфиболитов свидетельствуют о существовании в Чунозёрской зоне супракрустальных пород (как минимум, конгломерато-брекчий и метаэффузивов) до внедрения интрузии.

Метаморфические преобразования конгломерато-брекчий свидетельствуют о двух этавах метаморфизма. Термальный (палеопротерозойский) метаморфизм был наложен на более ранний (неоархейский) региональный метаморфизм. 
Ельяврские конгломерато-брекчии также как и руапнюнские рассматривается как «смешанные» вулканогенно-осадочные образования оползневого (турбидитового) типа, которые могли сформироваться в зонах проявления синхронного седиментогенеза и вулканизма (возможно, в задуговом бассейне?).

Конгломерато-брекчии Чунозёрской зоны по многим петрохимическим параметрам аналогичны конгломерато-брекчиям Вочеламбинского зеленокаменного пояса и расположены от них в 10 и 35 км западнее. Таким образом, руапнюнские конгломерато-брекчии могут быть генетическими, структурными, фациальными и возрастными аналогами «вочеламбинских» конгломерато-брекчий второй толщи Вочеламбинского зеленокаменного пояса (ВЗП). Являясь реликтами прибрежных фаций оползневого (турбидитового) типа, вероятно, позднеархейского (позднелопийского) задугового бассейна, в котором осадконакопление происходило синхронно с вулканизмом, они свидетельствуют о широком развитии неоархейского палеобассейна.

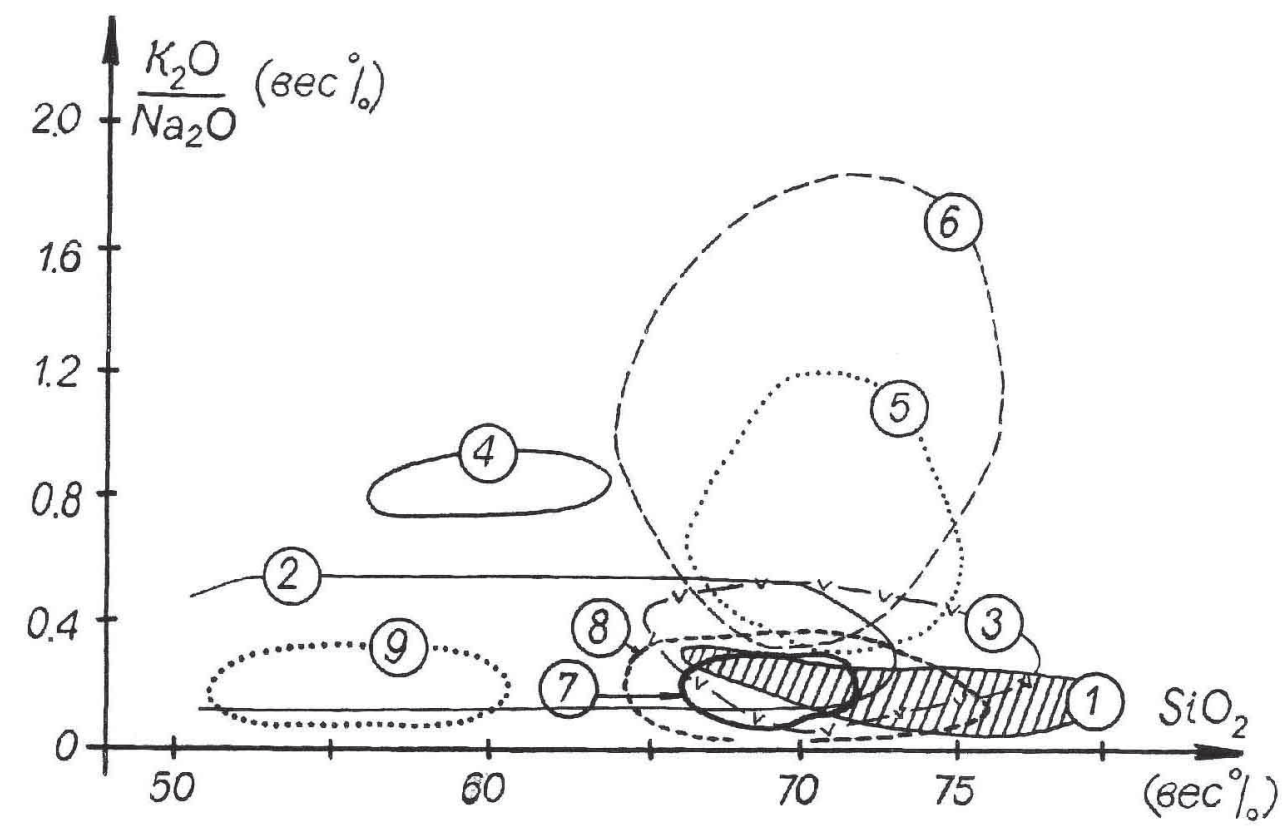

Рис. 5. Диаграмма $\mathrm{K}_{2} \mathrm{O} / \mathrm{Na}_{2} \mathrm{O}-\mathrm{SiO}_{2}$ : сопоставление состава галек и обломков конгломератобрекчий Чунозёрской зоны с основными типами гранитоидов Кольского региона.

1-6 - поля фигуративных точек анализов пород по (Виноградов, Свириденко, 1979): 1 - гальки древнейших конгломератов; 2 - пироксенсодержащие гранитоиды; 3 - биотитиовые и амфибол-биотитовые тоналиты и плагиограниты; 4 - кварцевые порфириты и гранодиоритпорфириты; 5 - гранодиориты; 6 - микроклинизированные плагиогранито-гнейсы и порфиробластические граниты-метасоматиты по древнейшим гранитоидам. 7-9 - поля фигуративных точек анализов галек и обломков конгломератобрекчий Чунозёрской зоны: галек плагиогранитов (7) и обломков метабазитов (9) конгломератобрекчий участка г. Руапнюн; галек плагиогранитов (8) конгломератобрекчий Вочеламбинского полигона Чунозёрской зоны.

Fig. 5. $\mathrm{K}_{2} \mathrm{O} / \mathrm{Na}_{2} \mathrm{O}-\mathrm{SiO}_{2}$ diagram: comparison of the composition of pebbles and fragments of breccia conglomerates in the Chunozero zone with the main types of granitoids in the Kola region.

1-6 - fields of figurative points of analysis of the rocks (Vinogradov, Sviridenko, 1979): 1 - pebbles of the oldest conglomerates; 2 - pyroxene - containing granitoids; 3 - biotite and amphibole-biotite tonalites and plagiogranites; 4 - quartz porphyritic and granodiorite porphyritic; 5 - granodiorites; 6 - microclinized plagiogranite-gneiss and porphyroblastic granites-metasomatites from the oldest granitoids. 7-9 - fields of figurative points of analyses of pebbles and fragments of conglomerate-breccias from the Chunozero zone: stones of plagiogranites (7) and fragments of metabasites (9) conglomerate-breccias on the Ruapnyun mountain; pebbles of plagiogranites (8) conglomeratebreccias of the Voche-Lambina polygon, Chunozero zone. 


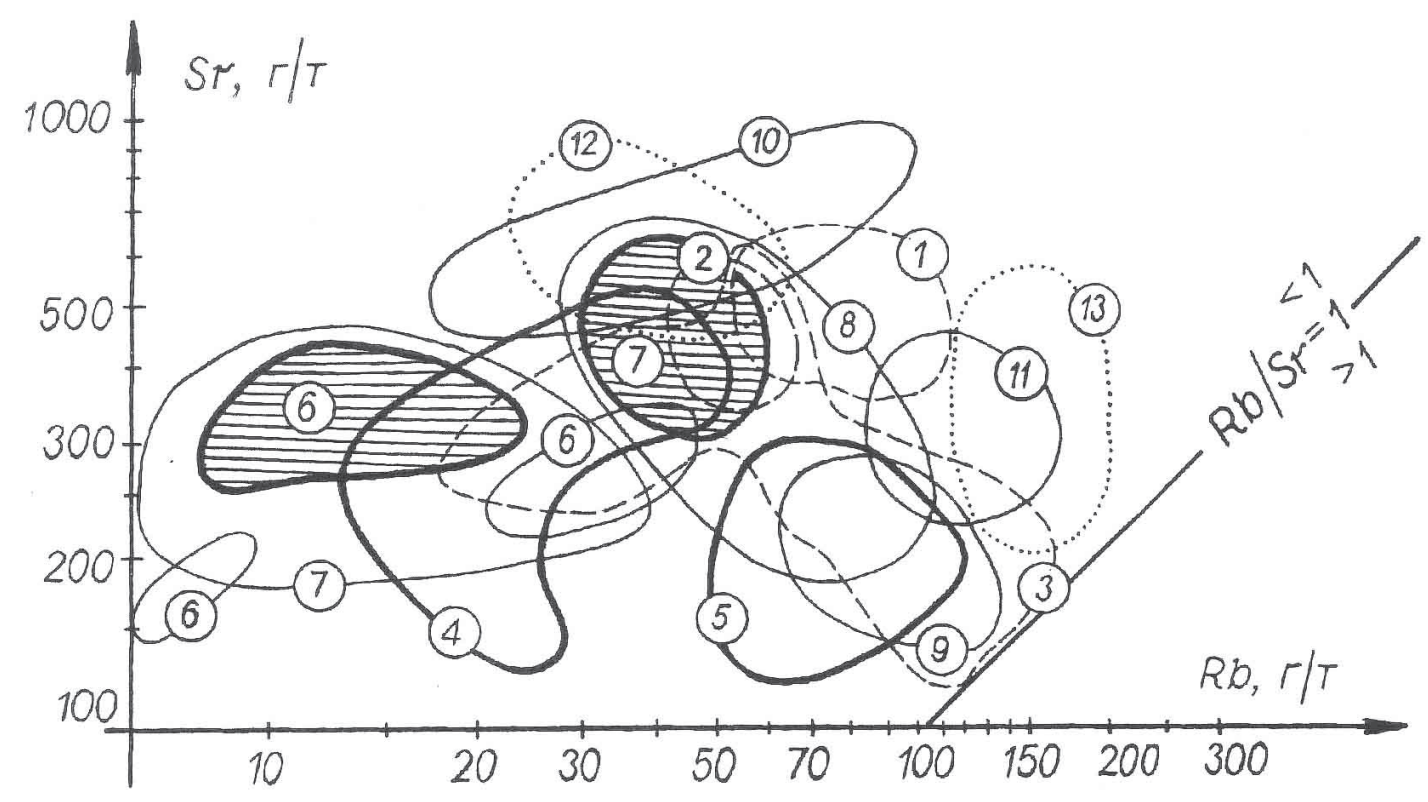

Рис. 6. Диаграмма $(\mathrm{Sr}-\mathrm{Rb})$ : сопоставление пород Чунозёрской зоны с породами Вочеламбинского полигона, гранитоидами Терского блока Кольского региона и гранитоидами раннего докембрия мира.

I - поля фигуративных точек анализов (Крылова, Лобач-Жученко, 1977) (штрих-пунктирные линии): 1 - олигоклазовые граниты Карелии; 2 - тоналиты плутонов Барбертон, Южная Африка; 3 - граниты Готхоб, ЮгоЗападная Гренландия. II - поля фигуративных точек анализов пород Чунозёрской зоны (жирные линии): 4 - габбро и метагаббро; 5 - метаандезитодациты Кислой губы; 6 - обломки метабазитов и 7 - гальки плагиогранитов вконгломерато-брекчий участка «Руапнюн». III - поля фигуративных точек анализов пород полигона «Вочеламбина» (Воче-Ламбинский архейский..., 1991) (тонкие линии): 6 - эклогиты; 7 - габбро, метагаббро и габбро-диабазы; 8 - плагиограниты $\gamma_{1-3} ; 9$ - гнейсы по метадацитам; 10 - гранитоиды $\gamma_{4-8} ; 11$ - плагиомикроклиновые гранитоиды. IV - поля фигуративных точек анализов пород Терского блока Кольского региона (точечные линии): 12 - плагиограниты и тоналиты; 13 - плагиомикроклиновые гранитоиды.

Fig. 6. Diagram $(\mathrm{Sr}-\mathrm{Rb})$ : comparison of species of the Chunozero zone with rocks of the Voche-Lambina polygon, granitoids of the Tersky block of the Kola region and the Early Precambrian granitoids in the world.

I - fields of figurative points of analyses (Krylova, Lobach-Zhuchenko, 1977) (dashed lines): 1 - oligoclase granites of Karelia; 2 - tonalites of plutons of Barberton, South Africa; 3 - Gothob granites, South-West Greenland. II - fields of figurative points of analyses of rocks from the Chunozero zone (bold line): 4 - gabbro and metagabbro; 5 - meta andesitodacites of the Kislaya Guba; 6 - fragments of meta-and 7 - plagiogranites pebbles of the conglomerate breccias site «Ruapnyun». III - fields of figurative points of analysis of rocks of the Vochelambina polygon (Vochelambina Archean..., 1991) (thin lines): 6 - eclogites; 7 - gabbro, metagabbro and gabbro-diabases; 8 - plagiogranites $\gamma_{1}$. ; $; 9$ - gneisses on metadacites; 10 - granitoids $\gamma_{4-8} ; 11$ - plagiomicrocline granitoids. IV - fields of figurative points of analysis of rocks of the Terskiy block of the Kola region (point lines): 12 - plagiogranites and tonalites; 13 - plagiomicrocline granitoids.

\section{Литература}

1. Виноградов А.Н., Свириденко Л.П. Раннедокембрийские конгломераты Балтийского щита, как индикаторы исходного состава первичнокоровых гранитов // Древнейшие гранитоиды Балтийского щита. Апатиты: изд. Кольского филиала АНСССР. 1979. С. 43-50.

2. Воче-Ламбинский архейский геодинамический полигон Кольского полуострова (ред.: Ф.П. Митрофанов, В.И. Пожиленко). Апатиты. Изд-во:КНЦ РАН. 1991. 140 с.

3. Кислицын Р.В., Балаганский В.В., Манттари И., Ганнибал Л.Ф., Пожиленко В.И., Рюнгенен Г.И. $\mathrm{U}-\mathrm{Pb}$-возрат цирконов из габброноритов и габброанортозитов полигона Воче-Ламбина. Кольский п-ов // Вестн. МГТУ. Т. 3. № 2. 2000. С. 307-314.

4. Крылова И.Н., Лобач-Жученко С.Б. Рубидий и стронций в древних гранитах и метавулканитах Центральной Карелии // Проблемы датирования докембрийских образований. Л. Изд-во: Наука. 1977. С. 211-224. 
5. Лунёва О.И. Докембрийские конгломераты Кольского полуострова. М. Изд-во: Наука. 1977. 220 с.

6. Пожиленко В.И., Гавриленко Б.В., Жиров Д.В., Жабин С.В. Геология рудных районов Мурманской области (под ред. Митрофанова Ф.П., Бичука Н.И.). Апатиты. Изд-во: КНЦ РАН. 2002. 359 с.

7. Пожиленко В.И. Раннедокембрийские конгломератобрекчии Чунозерской зоны: новые данные // Материалы международной научно-технической конференции «Наука и образование - 2007». Мурманск. Изд-во: МГТУ. 2007 а. С. 279-283. http://vestnik.mstu.edu.ru.

8. Пожиленко В.И. Раннедокембрийские конгломерато-брекчии и эруптивные брекчии Чунозерской зоны (Кольский п-ов): новые данные // Материалы Всероссийской конференции «Геодинамика, магматизм, седиментогенез и минерагения Северо-запада России». Петрозаводск. Изд-во: КарНЦ РАН. 2007 б. С. 303-306. 